\title{
Investigation the effect of weightlifting training on apelin level and hematologic parameters of professional handball players.
}

\author{
Aykut Dundar $^{1 *}$, Fatih Murathan ${ }^{1}$, Zait Burak Aktug ${ }^{2}$, Tayfun Servi ${ }^{3}$ \\ ${ }^{1}$ Physical Education and Sports College, Adiyaman University, Adiyaman, Turkey \\ ${ }^{2}$ Omer Halisdemir University, Sports College, Nigde, Turkey \\ ${ }^{3}$ Faculty of Economics and Administrative Sciences, Adiyaman University, Adiyaman, Turkey
}

\begin{abstract}
Objectives: Apelin is a member of myokines which has recently been characterized. The purpose of this study was to examine the effects of a weightlifting training (WT) program on some biochemical (glucose, insulin and apelin) and haematological parameters in professional male handball players. It was hypothesized that significant increase would be found in apelin levels of subjects

Material and methods: Ten professional handball players (Trained Handball Player Group, THG) completed 6-week WT. Ten sedentary subjects (Trained Sedentary Group, TSG) also completed WT to compare with THG and investigate the effect of being a handball player. Ten subjects have been considered as control group (Control Group, CG).

Results: The apelin levels of THG and TSG have been increased significantly $(p<0.05)$ but the increase in THG (55\%) is more than TSG (38\%). CG subjects did not exhibit any significant changes during the 6week period $(\mathbf{p}>\mathbf{0 . 0 5})$.

Conclusion: It has been concluded that the WT has an important role on apelin level, especially in professional handball players.
\end{abstract}

Keywords: Apelin, Weightlifting training, Hematologic parameters, Professional team handball.

Accepted on October 24, 2017

\section{Introduction}

Team handball has been one of the most popular team sports at both national and international levels during the last sixty years [1]. Competitive team handball requires muscular strength, speed and endurance but it is not very clear that how these parameters change during the different exercise programs and season [2]. The lack of experimental data (haematological, biochemical or hormonal parameters of blood samples) on professional team handball players is one of the most important reasons for this phenomenon.

However, the haematological parameters and biochemical characteristics can be crucial for predicting optimal physical performance $[3,4]$ there is not enough study which concerns these parameters about professional team handball players.

There is a very strong relationship between the muscle activity (exercises) and different body properties (mood, physical performance, haematological parameters and cognitive function) [5-8]. Some of the effects of different exercises including lower blood pressure, improved glucose homeostasis and lipid profile, higher resting energy expenditure and reduced fat mass [6-8]. There are several explanations for these benefits of exercise like increasing nutrient metabolism in various tissues by regulating the expression and activity of key metabolic control genes, leading to enhanced insulin sensitivity and metabolic flexibility [9]. But there is one more interesting issue, which is still unclear, the skeletal muscle exhibits remarkable metabolic adaptations to exercise [10,11]. Myokines, which are secreted in response to exercise and can regulate the function of muscle and other organs, may be one of the most sensible explanations [12].

Myokines are cytokines produced by skeletal muscles, especially induced by exercise, modulating different metabolic processes [13]. There are many well documented myokines like interleukin (IL6) and myostatin (MSTN) [14-16]. Apelin is a newly described myokine $[17,18]$. Production of apelin is induced by exercise and can behave as an exercise regulated myokine with autocrine-paracrine action [6]. Apelin is also related with insulin that is why it contributes to glucose homeostasis [19] and highly implicated in cardiovascular functions [20].

Hematologic parameters and apelin are clearly involved in exercise-associated metabolic changes, but also can be potentially effective in performance improvements of professional team handball players during weightlifting training [7]. We aimed to analyse the fluctuations of some 
biochemical (glucose, insulin and apelin) and hematologic parameters in professional team handball players and sedentary individuals after WT.

\section{Methods}

This study has been approved by the "Ethical Committee of Biomedical Researches" of Adiyaman University (Date: 25/03/2015, No: 2015/02-20, Chair Person: Prof. Dr. Haydar Bagis). All subjects were informed of the benefits and risks of the investigation.

\section{Experimental approach}

There are three groups of subjects in this study. The first group includes professional team handball players (THG: Trained handball group), second is sedentary group (TSG: Trained sedentary group) (who are not sportsmen) and the third group is control group (CG) (who are not sportsmen and did not train). The members of THG have been chosen from a city handball team which is a professional handball team in best league of related country. Each group composes from 10 subjects (totally 30 subjects). First group (THG) and second group (TSG) have performed WT three days in a week for six weeks (totally 18 training days). In the first training day of each week the subjects performed $3 \times 10$ bench press, $3 \times 10$ incline bench press, $3 \times 10$ dumbbells flyes, $3 \times 10$ butterfly, 3 $\times 10$ pullover for chest workout and $3 \times 10$ squad, $3 \times 10$ leg extension, $3 \times 10$ leg lying curl, $3 \times 12$ standing calf raises for leg workout. In second training day $3 \times 10$ shoulder press, $3 \times$ 10 front raise, $3 \times 10$ dumbbell side lateral raises, $3 \times 10$ upright barbell rowing for shoulder workout and $3 \times 10$ lying triceps extension, $3 \times 10$ seated overhead, $3 \times 10$ standing cable push down for triceps workout performed by THG and TSG. In the third training day $3 \times 10$ lat machine pull down, 3 $\times 10$ cable row seated, $3 \times 10$ T-bar rowing for back workout, 3 $\times 10$ standing barbell curl, $3 \times 10$ preacher curl, $3 \times 10$ concentration curl for biceps workout and $3 \times 12$ wrist curl for wrist workout performed by all subjects.

Blood samples of all groups have been analysed before and after the training period. The blood samples of CG have been also analysed to exclude the external factors (temperature, etc.). The blood samples have been analysed by means of haematological parameters (WBC, RBC, etc) and biochemical parameters (glucose, insulin and apelin). The differences have been calculated between two analyses (before and after weightlifting training) for each group. Calculated differences were considered to analyse the effect of WT to THG and TSG. Calculated differences subtracted, and the results were analysed statistically to understand if the weightlifting training has a meaningful effect on haematological parameters, insulin, glucose or apelin levels of THG (Table 1).

The averages of dTHG, dTSG and dCG were examined to understand the effect of WT to a single group, and averages of dTHG-dTSG was studied with a multi comparison (Benferroni) test to investigate if the WT has a special meaning on THG. dTSG-dCG parameter has also been considered to understand the effect of WT on non-sportsmen.

Table 1. A representative table to explain the statistical methodology (BT: before training, AT: after training, WBC: chosen hematologic parameter).

\begin{tabular}{llll}
\hline & WBC (BT) & WBC (AT) & Differences \\
\hline THG & a & d & a-d=dTHG \\
\hline TSG & b & e & b-e=dTSG \\
\hline CG & $c$ & f & $c-f=d C G$ \\
\hline
\end{tabular}

The age, height, weight and body/fat averages were reported with standard errors on Table 2 for each group.

Table 2. Weight, age, and body/fat \% averages for each group, BT: before weightlifting training, AT: after weightlifting training.

\begin{tabular}{lllllll}
\hline \multicolumn{2}{l}{ Weight $(\mathrm{kg})$} & \multicolumn{2}{l}{ Age } & \multicolumn{3}{l}{ Body/fat $\%$} \\
\hline BT & AT & BT & AT & BT & AT \\
\hline THG & 79.575 & 81.115 & 20.9 & 20.9 & 15.426 & 13.548 \\
\hline TSG & 76.598 & 76.853 & 20.6 & 20.6 & 14.493 & 13.276 \\
\hline CG & 78.391 & 77.286 & 20.4 & 20.4 & 15.353 & 15.142 \\
\hline
\end{tabular}

\section{Statistical analysis}

Descriptive statistics were reported for all groups. A $3 \times 2$ (group x time) repeated measures analysed with ANOVA. Oneway analysis of variance (ANOVA) was used to examine if there is a significant correlation between any two of three groups (THG, TSG and CG). If significant $F$ values were determined, paired comparisons combined with a Bonferroni post hoc adjustment to determine differences. Raw difference scores were analysed with the use of a 1-way ANOVA. Pearson's product moment correlation coefficient was used to investigate the relationship between selected variables. Statistical significance was set at $\mathrm{p}<0.05$. All statistical analyses were performed using SPSS [21].

\section{Blood collection}

Blood samples were collected from participants 30 minutes prior to first WT and within 30 minutes after the last WT. Twenty milliliters of blood was collected during each blood draw using one heparinized $10 \mathrm{~mL}$ tube and one $10-\mathrm{mL}$ ethylenediaminetetraacetic acid tube. Plasma was isolated from the heparinized blood by centrifugation.

THG represents the weightlifting trained professional handball players, TSG represents the weightlifting trained sedentary group (not sportsman) and the CG represents non-trained sedentary participants. So, the comparison of TSG and CG was provided information about the effect of WT on hematologic and biochemical parameters of sedentary group and the comparison of THG and TSG was provided information about 
the effect of being a professional handball player because both THG and TSG performed same WT.

\section{Results}

Basically, two kinds of data were reported and discussed. The first one is the comparison of groups (table 1, between groups, dTHG-dTSG). The other is the differences between two blood sample analyses (dTHG and dTSG) in each group.

\section{1st data type (between groups)}

The statistical analysis of the groups (THG and TSG) provided useful information that how the weightlifting training effects the hematologic (WBC, RBC, PLT, HGB, HCT, MCH and PCT) and biochemical (glucose, insulin and apelin) parameters in professional handball players and sedentary individuals.

The one-way analyses, ANOVA test and multiple comparison Bonferroni post hoc adjustment have been reported on table 3 . A "p" value $<0.05$ was considered significant in all analyses.

The first column on table 3 represents the analysed haematological parameters. "p" represents the statistical significance and tells that there is a meaningful correlation between groups, when smaller than 0.05 . The other columns of table 3 gives chance to understand which groups are correlated, because there are three groups (THG, TSG and CG) and it should be clearly understood that which two of these three groups are correlated. The starred $(*)$ numbers in "Mean Difference" column shows the correlated groups.

\section{2nd data type (within groups)}

A paired samples test has been performed for each group. The statistical analysis results let us to compare analysis of each blood parameter before and after WT. It has been concluded that a significant change observed at four hematologic parameters (WBC, $\mathrm{p}=0.000$; RBC, $\mathrm{p}=0.002$; PLT, $\mathrm{p}=0.001$ and HGB, $p=0.000$ ) and three biochemical parameters (glucose, $p=0.000$; insulin; $p=0.000$ and apelin, $p=0.000$ ) for THG. None of these significant changes have been observed for hematologic parameters of TSG (all $\mathrm{p}$ values are higher than 0.05 ) but the biochemical parameters have changed significantly like THG (glucose, $p=0.000$; insulin; $p=0.001$ and apelin, $p=0.000$ ). And finally, none of the hematologic and biochemical parameters changed significantly for CG.

\section{Discussion}

The most important result of this study was that the WT, which has been going on for six weeks, significantly changed the glucose, insulin and apelin levels of both THG and TSG but the apelin level of THG (55\%) has been increased more than TSG (38\%) (Figure 1). The different amount of muscle tissues of professional team handball players and sedentary group may be the main reason for this phenomenon. It is clear that apelin is produced by skeletal muscles and induced by exercise $[6,13]$. So, although the two-analysed group (THG and TSG) have been performed the same training the apelin level of
THG, who have more muscle tissue because this group includes professional handball players, has increased more than TSG.

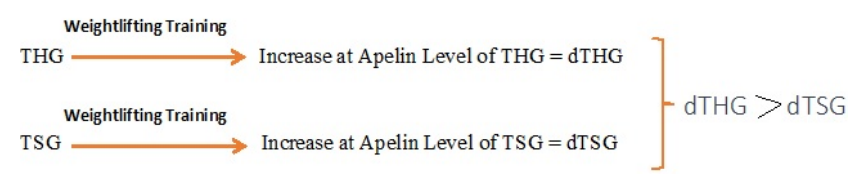

Figure 1. Schematically comparison of apelin level increase of groups (THG and TSG) after WT.

This is an important result because apelin is a newly described myokin and such findings to our knowledge are the first to demonstrate that a significant upregulation of serum apelin levels after WT in professional handball players. The result of this study supports a previous study on apelin levels of a diabetic population after exercise treatment [22]. A significant increase in levels of plasma IL-6, which is a well described myokine, has been reported [22] and this result is also supporting our results about apeline increase with training.

By means of group comparison (THG and TSG) it has been concluded that a significant increase in four haematological parameters of (WBC, RBC, PLT and HGB) have been observed (Table 3). WBC, RBC, PLT and HGB parameters of THG have been increased $34 \%, 9 \%, 22 \%$ and $8 \%$ respectively after the WT. There is no significant change in any hematologic parameter of TSG. These results confirm a previous study on the effect of exercise on haematological parameters [23].

In case of $\mathrm{WBC}$ while there is a meaningful change between THG and TSG, there is no such relation between TSG and CG. Thus, it can be concluded that WT has no effect on WBC level of sedentary participants but being a professional handball player is a significant factor. While same interpretation can be done for PLT level, there is no such relation between groups for RBC and HGB parameters (Table 3). P values of RBC and HGB are smaller than 0.05 but this result can't be interpreted because the relations ("*" on table 3 ) are between THG and CG. It is not clear that what is the driving factor for the differences of related parameters (RBC and HGB) between THG and CG, WT or being a handball player? There are not enough data to interpret this phenomenon.

Table 3. One way analyze, ANOVA test $(p<0.05)$ and multiple comparison Bonferroni post hoc adjustment of hematologic parameters $(N=$ number of subjects, Mean= average of differences (AT-BT) with standard errors, $p=$ statistical significance).

\begin{tabular}{|c|c|c|c|c|c|c|c|}
\hline \multicolumn{4}{|l|}{ Descriptive } & \multicolumn{4}{|c|}{${ }^{* *}$ Multiple Comparisons (Bonferroni) } \\
\hline & $N$ & Mean & $p$ & $\begin{array}{l}\text { (I) } \\
\text { Group }\end{array}$ & $\begin{array}{l}(\mathrm{J}) \\
\text { Group }\end{array}$ & $\begin{array}{l}\text { Mean } \\
\text { Difference (I-J) }\end{array}$ & Sig. \\
\hline \multirow[t]{2}{*}{ WBC THG } & 10 & $2.0 \pm 0.1$ & $\begin{array}{l}0.00 \\
0\end{array}$ & THG & CG & $2.0 \pm 0.2^{*}$ & $\begin{array}{l}0.00 \\
0\end{array}$ \\
\hline & & & & & TSG & $2.2 \pm 0.2^{*}$ & $\begin{array}{l}0.00 \\
0\end{array}$ \\
\hline
\end{tabular}


Dundar/Murathan/Aktug/Servi

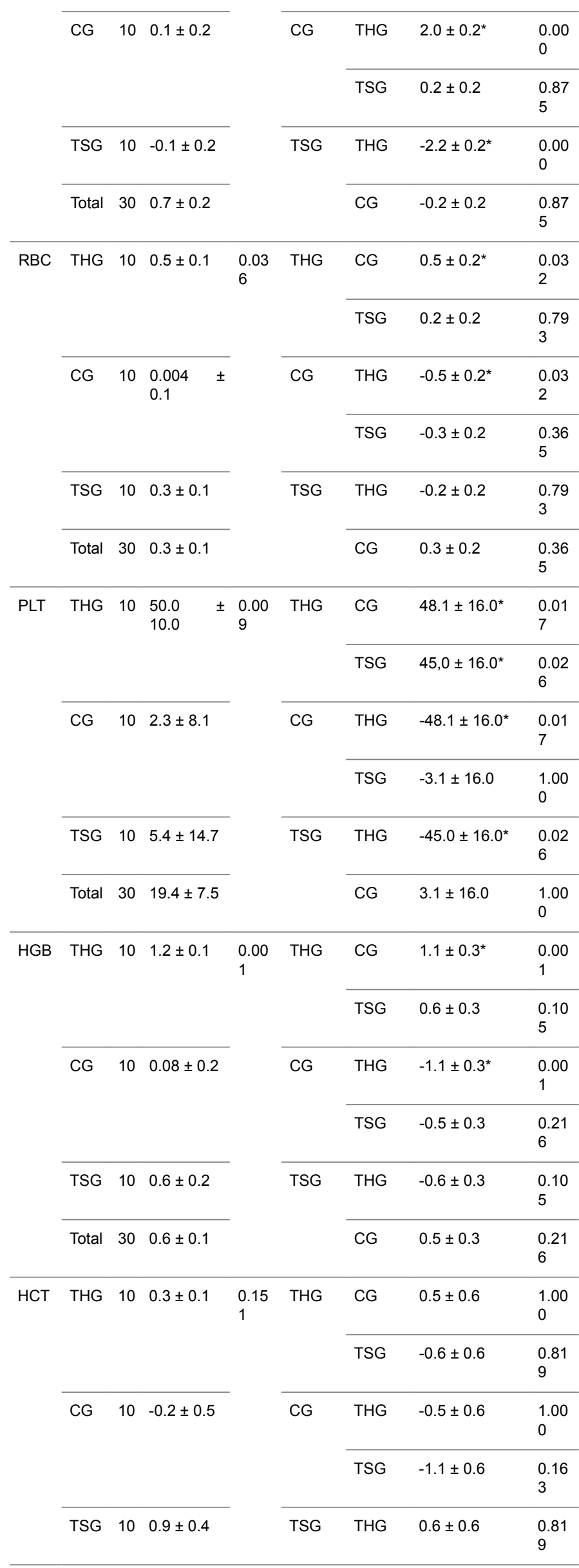

\begin{tabular}{|c|c|c|c|c|c|c|c|c|c|}
\hline & Total & 30 & $0.3 \pm 0.2$ & & & & CG & $1.1 \pm 0.6$ & $\begin{array}{l}0.16 \\
3\end{array}$ \\
\hline \multirow[t]{6}{*}{$\mathrm{MCH}$} & THG & 10 & $0.3 \pm 0.1$ & & $\begin{array}{l}0.57 \\
9\end{array}$ & THG & CG & $-0.1 \pm 0.3$ & $\begin{array}{l}1.00 \\
0\end{array}$ \\
\hline & & & & & & & TSG & $-0.3 \pm 0.3$ & $\begin{array}{l}0.93 \\
9\end{array}$ \\
\hline & CG & 10 & $0.3 \pm 0.2$ & & & CG & THG & $0.1 \pm 0.3$ & $\begin{array}{l}1.00 \\
0\end{array}$ \\
\hline & & & & & & & TSG & $-0.2 \pm 0.3$ & $\begin{array}{l}1.00 \\
0\end{array}$ \\
\hline & TSG & 10 & $0.6 \pm 0.3$ & & & TSG & THG & $0.3 \pm 0.3$ & $\begin{array}{l}0.93 \\
9\end{array}$ \\
\hline & Total & 30 & $0.4 \pm 0.1$ & & & & CG & $0.2 \pm 0.3$ & $\begin{array}{l}1.00 \\
0\end{array}$ \\
\hline \multirow[t]{6}{*}{ PCT } & THG & 10 & $\begin{array}{l}0.004 \\
0.002\end{array}$ & \pm & $\begin{array}{l}0.65 \\
0\end{array}$ & THG & CG & $-0.003 \pm 0.007$ & $\begin{array}{l}1.00 \\
0\end{array}$ \\
\hline & & & & & & & TSG & $-0.007 \pm 0.007$ & $\begin{array}{l}1.00 \\
0\end{array}$ \\
\hline & CG & 10 & $\begin{array}{l}0.007 \\
0.006\end{array}$ & \pm & & CG & THG & $0.003 \pm 0.007$ & $\begin{array}{l}1.00 \\
0\end{array}$ \\
\hline & & & & & & & TSG & $-0.003 \pm 0.007$ & $\begin{array}{l}1.00 \\
0\end{array}$ \\
\hline & TSG & 10 & $\begin{array}{l}0.01 \\
0.006\end{array}$ & \pm & & TSG & THG & $0.007 \pm 0.007$ & $\begin{array}{l}1.00 \\
0\end{array}$ \\
\hline & Total & 30 & $\begin{array}{l}0.007 \\
0.02\end{array}$ & \pm & & & CG & $0.003 \pm 0.007$ & $\begin{array}{l}1.00 \\
0\end{array}$ \\
\hline
\end{tabular}

THG, TSG and CG have been compared by means of three biochemical parameters (glucose, insulin and apelin) on Table 4. It can be concluded that both WT and being a professional handball player are effective on glucose, insulin and apelin levels because all values are marked with a star $(*)$ in "Mean Difference" column of multiple comparison Bonferroni test (Table 4).

Table 4. One way analyze ANOVA test $(p<0.05)$ and multiple comparison Bonferroni post hoc adjustment of glucose, insulin and apeline.

\begin{tabular}{|c|c|c|c|c|c|c|c|c|}
\hline \multicolumn{5}{|c|}{ Descriptive } & \multicolumn{4}{|c|}{ Multiple Comparisons (Bonferroni) } \\
\hline & & $\mathrm{N}$ & Mean & $\mathrm{p}$ & $\begin{array}{l}\text { (I) } \\
\text { Group }\end{array}$ & $\begin{array}{l}(\mathrm{J}) \\
\text { Group }\end{array}$ & $\begin{array}{l}\text { Mean } \\
\text { Difference } \\
(\mathrm{I}-\mathrm{J})\end{array}$ & Sig. \\
\hline \multirow[t]{4}{*}{$\begin{array}{l}\text { Glucos } \\
\mathrm{e}\end{array}$} & THG & $\begin{array}{l}1 \\
0\end{array}$ & $13.0 \pm 1.0$ & $\begin{array}{l}0.00 \\
0\end{array}$ & THG & CG & $12.2 \pm 1.1^{*}$ & $\begin{array}{l}0.00 \\
0\end{array}$ \\
\hline & & & & & & TSG & $9.3 \pm 1.1^{*}$ & $\begin{array}{l}0.00 \\
0\end{array}$ \\
\hline & CG & $\begin{array}{l}1 \\
0\end{array}$ & $0.8 \pm 0.6$ & & CG & THG & $-12.2 \pm 1.1^{*}$ & $\begin{array}{l}0.00 \\
0\end{array}$ \\
\hline & & & & & & TSG & $-3.0 \pm 1.1^{*}$ & $\begin{array}{l}0.04 \\
5\end{array}$ \\
\hline
\end{tabular}


players

\begin{tabular}{|c|c|c|c|c|c|c|c|c|}
\hline & TSG & $\begin{array}{l}1 \\
0\end{array}$ & $3.7 \pm 0.7$ & & TSG & THG & $-9.3 \pm 1.1^{*}$ & $\begin{array}{l}0.00 \\
0\end{array}$ \\
\hline & Total & $\begin{array}{l}3 \\
0\end{array}$ & $5.8 \pm 1.1$ & & & CG & $2.9 \pm 1.1^{*}$ & $\begin{array}{l}0.04 \\
5\end{array}$ \\
\hline \multirow[t]{6}{*}{ Insulin } & THG & $\begin{array}{l}1 \\
0\end{array}$ & $-4.0 \pm 1.1$ & $\begin{array}{l}0.00 \\
0\end{array}$ & THG & CG & $-3.7 \pm 0.4^{*}$ & $\begin{array}{l}0.00 \\
0\end{array}$ \\
\hline & & & & & & TSG & $-2.0 \pm 0.4^{*}$ & $\begin{array}{l}0.00 \\
0\end{array}$ \\
\hline & CG & $\begin{array}{l}1 \\
0\end{array}$ & $-0.3 \pm 0.2$ & & CG & THG & $3.7 \pm 0.4^{*}$ & $\begin{array}{l}0.00 \\
0\end{array}$ \\
\hline & & & & & & TSG & $1.7 \pm 0.4^{*}$ & $\begin{array}{l}0.00 \\
3\end{array}$ \\
\hline & TSG & $\begin{array}{l}1 \\
0\end{array}$ & $-2.0 \pm 0.4$ & & TSG & THG & $2.0 \pm 0.4^{*}$ & $\begin{array}{l}0.00 \\
0\end{array}$ \\
\hline & Total & $\begin{array}{l}3 \\
0\end{array}$ & $-2.1 \pm 0.3$ & & & CG & $-1.7 \pm 0.4^{*}$ & $\begin{array}{l}0.00 \\
3\end{array}$ \\
\hline \multirow[t]{6}{*}{ Apelin } & THG & $\begin{array}{l}1 \\
0\end{array}$ & $\begin{array}{l}1289.3 \\
140.0\end{array}$ & $\begin{array}{l}0.00 \\
0\end{array}$ & THG & CG & $\begin{array}{l}1201.1 \\
143.6^{*}\end{array}$ & $\begin{array}{l}0.00 \\
0\end{array}$ \\
\hline & & & & & & TSG & $\begin{array}{l}515.9 \\
143.6^{*}\end{array}$ & $\begin{array}{l}0.00 \\
4\end{array}$ \\
\hline & CG & $\begin{array}{l}1 \\
0\end{array}$ & $88.2 \pm 63.0$ & & CG & THG & $\begin{array}{l}-1201.1 \quad \pm \\
143.6^{*}\end{array}$ & $\begin{array}{l}0.00 \\
0\end{array}$ \\
\hline & & & & & & TSG & $\begin{array}{l}-685,2 \\
143.6^{*}\end{array}$ & $\begin{array}{l}0.00 \\
0\end{array}$ \\
\hline & TSG & $\begin{array}{l}1 \\
0\end{array}$ & $773.4 \pm 86.0$ & & TSG & THG & $\begin{array}{l}-515,9 \\
143.6^{*}\end{array} \quad \pm$ & $\begin{array}{l}0.00 \\
4\end{array}$ \\
\hline & Total & $\begin{array}{l}3 \\
0\end{array}$ & $717.0 \pm 107.4$ & & & CG & $\begin{array}{l}685.2 \\
143.6^{\star}\end{array}$ & $\begin{array}{l}0.00 \\
0\end{array}$ \\
\hline
\end{tabular}

*Related groups by means of the differences (AT-BT) of haematological parameters.

Apelin is one of the responsible hormones for the occurrence and development of cardiovascular diseases [23] that is why the relationship between the WT and apelin should be well described.

\section{Conclusion}

The results of this study may help the professional handball coaches to associate the WT status and apelin levels of players. As a result of this study a strong relationship has been detected between the apelin levels and WT, especially in professional handball players.

\section{References}

1. Clanton R and Dwight MP. Team handball. Steps to success. Champaign, IL: Human Kinetics Books 1997; 23-38.

2. Marques MC. In season strength and power training for professional male team handball players. Str and Cond J 2010; 32: 74-81.

3. Andelkovic M, Baralic I, Dordevic B, Stevuljevic JK, Radivojevic N, Dikic N, Skodric SR, Stojkovic M. Hematological and biochemical parameters in elite soccer players during a competitive half season. J Med Biochem 33: 460-466, 2014.

4. Ibis S, Hazar S, Demirci I. The effect of plyometric training on hematological parameters in alpine skiers. Sport SPA 2012; 9: 15-19.

5. Bayram M, Göksu M. Effects of six-week endurance training method on some hematological values of basketball players. Nigde Univ J of Phy Ed And Spo Sci 2015; 9: 292-299.

6. Besse-Patin A, Montastier E, Vinel C, Castan-Laurell I, Louche K, Dray C, Daviaud D, Mir L, Marques MA, Thalamas C, Valet P, Langin D, Moro C, Viguerie N. Effect of endurance training on skeletal muscle myokine expression inobese men: identification of apelin as a novel myokine. Int J Obes 2014; 38: 707-713.

7. Gomara FS, Alisb R, Rampininid E, Bosio A, Feriolid D, La Torre A, Xuf J, Sansoni V, Perego S, Romagnoli M, Lombardi G. Adropin and apelin fluctuations throughout a season in professional soccer players: Are they related with performance? Peptides 2015; 70: 32-36.

8. Heisterberg MF, Fahrenkrug J, Krustrup P, Storskov A, Kjaer M, Andersen JL. Extensive monitoring through multiple blood samples in professional soccer players. J of Str And Cond Res 2013; 27: 1260-1271.

9. Egan B, Zierath JR. Exercise metabolism and the molecular regulation of skeletal muscle adaptation. Cell Metab 2013; 17: 162-184.

10. Hood DA. Mechanisms of exercise-induced mitochondrial biogenesis in skeletal muscle. Appl Physiol Nutr Metab 2009; 34: 465-472.

11. Holloszy JO. Regulation by exercise of skeletal muscle content of mitochondria and GLUT4. J Phy Pharm 2008; 59: 5-18.

12. Pedersen BK and Febbraio MA. Muscles, exercise and obesity: skeletal muscle as a secretory organ. Nat Rev End 2012; 8: 457-465.

13. Febbraio MA, Pedersen BK. Contraction-induced myokine production and release: is skeletal muscle an endocrine organ. Exerc Sport Sci Rev 2005; 33: 114-119.

14. Carey AL, Steinberg GR, Macaulay SL, Thomas WG, Holmes AG, Ramm G, Prelovsek O, Hohnen-Behrens C, Watt MJ, James DE, Kemp BE, Pedersen BK, Febbraio MA. Interleukin-6 increases insulin-stimulated glucose disposal in humans and glucose uptake and fatty acid oxidation in vitro via AMP-activated protein kinase. Diabetes 2006; 55: 2688-2697.

15. Febbraio MA. Signaling pathways for IL-6 within skeletal muscle. Exerc Immunol Rev 2003; 9: 34-39.

16. Mc Pherron AC, Lawler AM, Lee SJ. Regulation of skeletal muscle mass in mice by a new TGF-beta superfamily member. Nature 1997; 387: 83-90.

17. Kadoglou NP, Vrabas IS, Kapelouzou A, Lampropoulos S, Sailer N, Kostakis A, Liapis CD, Angelopoulou N. The impact of aerobic exercise training on novel adipokines, apelin andghrelin, in patients with type 2 diabetes. Med Sci Monit 2012; 18: 290-295. 
18. Pedersen BK, Febbraio M. Muscle-derived interleukin-6 - a possible link between skeletal muscle, adipose tissue, liver, and brain. Brain Behav Immun 2005; 19: 371-376.

19. Soriguer F, Garrido-Sanchez L, Garcia-Serrano S, GarciaAlmeida JM, Garcia-Arnes J, Tinahones FJ, Garcia-Fuentes E. Apelin levels are increased in morbidly obese subjects with type 2 diabetes mellitus. Obes Surg 2009; 19: 1574-1580.

20. Kadoglou NP, Lampropoulos S, Kapelouzou A, Gkontopoulos A, Theofilogian-nakos EK, Fotiadis G, Kottas G. Serum levels of apelin and ghrelin in patients with acute coronary syndromes and established coronary artery disease - KOZANI STUDY. Transl Res 2010; 155: 238-46.

21. IBM Corp. Released 2013. IBM SPSS Statistics for Windows, Version 22.0. Armonk, NY: IBM Corp.

22. Wardyna GG, Rennarda SI, Brusnahanb SK, McGuirec TR, Carlsona ML, Smithd LM, Mc Granaghana S, Sharp JG.
Effects of exercise on hematological parameters, circulating side population cells, and cytokines. Exp Hem 2008; 36: 216-223.

23. $\mathrm{Lu} \mathrm{L,} \mathrm{Wu} \mathrm{D,} \mathrm{Li} \mathrm{L,} \mathrm{Chen} \mathrm{L.} \mathrm{Apelin/APJ} \mathrm{system:} \mathrm{A}$ bifunctional target for cardiac hypertrophy. Int J Card 2017; 230: 164-170.

\section{*Correspondence to}

Aykut Dundar

Physical Education and Sports College

Altin Sehir Campus

Adiyaman University

Adiyaman, Turkey 